\title{
A atuação da Corte Interamericana de Direitos Humanos no que tange a grupos em situação de vulnerabilidade: Análise da Opinião Consultiva 24/2017(*)
}

\author{
El desempeño de la Corte Interamericana de Derechos Humanos en \\ relación con los grupos en situación de vulnerabilidad: Análisis de la \\ Opinión Consultiva 24/2017
}

\author{
The proceeding of the Inter-American Court of Human Rights regarding \\ vulnerable groups: An analysis of Advisory Opinion 24/2017
}

\author{
Mônia Clarissa Hennig Leal(**) \\ Universidade de Santa Cruz do Sul (Santa Cruz do Sul, Brasil) \\ Sabrina Santos Lima $\left.{ }^{(* *}\right)$ \\ Universidade de Santa Cruz do Sul (Santa Cruz do Sul, Brasil)
}

\begin{abstract}
Resumo: O Sistema Interamericano de Proteção aos Direitos Humanos está inserido em um contexto de busca pela máxima proteção e garantia de direitos humanos. Assim, além de uma Constituição Federal que traz no seu bojo a vontade de concretizar direitos humanos e fundamentais, tem-se ainda um Sistema Global e um Sistema Regional de Proteção, o que evidencia a relevância e atualidade do tema. Partindo-se dessa premissa, trabalha-se neste artigo com os conteúdos que abarcam o direito à não-discriminação e à igual proteção perante a lei, especialmente a partir da lógica da função consultiva exercida pela Corte Interamericana de Direitos Humanos. Nesse sentido, tem-se como problema o seguinte questionamento: qual o posicionamento adotado na Opinião Consultiva 24/2017 pela Corte Interamericana de Direitos Humanos, no que tange aos direitos da comunidade LGBT, enquanto grupo em situação de vulnerabilidade? Para tanto, utiliza-se o método de abordagem dedutivo, e objetiva-se, num primeiro momento, abordar a lógica de atuação da Corte Interamericana de Direitos Humanos, com foco na
\end{abstract}

$\left(^{*}\right) \quad$ Nota do Editor: Este artigo foi recebido em 5 de setembro de 2020 e aprovado para publicação em 29 de outubro de 2020.

$\left(^{* *}\right)$ Professora do Programa de Pós-Graduação em Direito - Mestrado e Doutorado da Universidade de Santa Cruz do Sul - UNISC (Santa Cruz do Sul, RS, Brasil), onde ministra as disciplinas de Jurisdição Constitucional e de Políticas Públicas, respectivamente. Doutorado em Direito pela Universidade do Vale do Rio dos Sinos - Unisinos (São Leopoldo, RS, Brasil), com pesquisas realizadas junto à Ruprecht-Karls Universität Heidelberg, na Alemanha. Pós-Doutorado na Ruprecht-Karls Universität Heidelberg (Alemanha). Coordenadora do Grupo de Pesquisa "Jurisdição Constitucional aberta", vinculado ao CNPq. Bolsista de produtividade em pesquisa do CNPq. ORCID: http://orcid.org/0000-0002-3446-1302. Lattes: http://lattes.cnpq.br/6628165246247243. Correio eletrônico: moniah@ unisc.br

${ }^{* * *}$ Doutoranda no Programa de Pós-Graduação Stricto Sensu em Direitos Sociais e Políticas Públicas da Universidade de Santa Cruz do Sul - UNISC, no eixo Dimensões Instrumentais das Políticas Públicas. Bolsista PROSUC/CAPES. Mestre em Direito pela Universidade de Santa Cruz do Sul - UNISC, na linha de pesquisa Constitucionalismo Contemporâneo, com bolsa PROSUC/CAPES. Professora de Direito na Faculdade Dom Alberto. Servidora Pública do Município de Santa Cruz do Sul/RS. Membro do Grupo de Pesquisa "Jurisdição Constitucional aberta: uma proposta de discussão da legitimidade e dos limites da jurisdição constitucional instrumentos teóricos e práticos", vinculado ao CNPq e coordenado pela professora Pós-Dra. Mônia Clarissa Hennig Leal. ORCID: http://orcid.org/0000-0003-2863-1755. Lattes: http://lattes.cnpq.br/9782118834420014. Correio eletrônico: sa._94@hotmail.com 
A atuação da Corte Interamericana de Direitos Humanos no que tange a grupos em situação de vulnerabilidade: Análise da Opinião Consultiva 24/2017

El desempeño de la Corte Interamericana de Derechos Humanos en relación con los grupos en situación de vulnerabilidad: Análisis de la Opinión Consultiva 24/2017

The proceeding of the Inter-American Court of Human Rights regarding vulnerable groups: An analysis of Advisory Opinion 24/2017

sua função consultiva; verificar os principais aspectos no que tange à proteção dos grupos em situação de vulnerabilidade sob a ótica da Convenção Americana; e, por fim, analisar criticamente a Opinião Consultiva 24/2017, emitida pela Corte, que versa sobre a proteção que deve ser conferida pelos Estados à comunidade LGBT. Conclui-se, ao final, que a Corte compreende que os Estados devem adotar medidas de proteção a esse grupo, evitando qualquer tipo de discriminação e erradicando, ou ao menos reduzindo, as violências que decorrem da identidade de gênero e sexual.

Palavras-chave: Comunidade LGBT - Corte Interamericana de Direitos Humanos - Grupos em situação de vulnerabilidade - Função consultiva - Opinião Consultiva 24/2017 - Sistema Interamericano

Resumen: El Sistema Interamericano de Protección de los Derechos Humanos se inserta en un contexto de búsqueda de la máxima protección y garantía de los derechos humanos. Así, además de una Constitución Federal que trae consigo la voluntad de materializar los derechos humanos y fundamentales, también existe un Sistema Global y un Sistema de Protección Regional, que resalta la relevancia y actualidad del tema. Con base en esta premisa, este artículo aborda los contenidos que engloban el derecho a la no discriminación y a la igual protección ante la ley, especialmente a partir de la lógica del rol consultivo que ejerce la Corte Interamericana de Derechos Humanos. En este sentido, surge como problema la siguiente pregunta: ¿cuál es la posición adoptada en la Opinión Consultiva 24/2017 por la Corte Interamericana de Derechos Humanos, respecto a los derechos de la comunidad LGBT, como grupo vulnerable? Para ello se utiliza el enfoque deductivo, y el objetivo es, en un primer momento, atender la lógica operativa de la Corte Interamericana, enfocándose en su función consultiva; verificar los principales aspectos relacionados con la protección de grupos en situación de vulnerabilidad bajo la perspectiva de la Convención Americana; y, finalmente, analizar críticamente la Opinión Consultiva 24/2017, emitida por la Corte, que trata sobre la protección que deben brindar los Estados a la comunidad LGBT. Se concluye, finalmente, que la Corte entiende que los Estados deben adoptar medidas para proteger a este grupo, evitando cualquier tipo de discriminación y erradicando, o al menos reduciendo, la violencia que se deriva de la identidad de género y sexual.

Palabras clave: Comunidad LGBT - Corte Interamericana de Derechos Humanos - Grupos vulnerables - Función consultiva Opinión Consultiva 24/2017 - Sistema Interamericano

Abstract: The Inter-American Human Rights System is inserted in a context of searching for the maximum protection and guarantee of human rights. Therefore, in addition to a Federal Constitution that aims to grant human and fundamental rights, there is also a Global System and a Regional Protection System, which highlights the relevance and timeliness of the matter. Based on the premise, this article studies the contents of the right of non-discrimination and equal protection before the law, especially from the logicality of the advisory role exercised by the InterAmerican Court of Human Rights. This way, the following issue arises: what is the position adopted in the Advisory Opinion 24/2017 by the Inter-American Court of Human Rights, in regard to the rights of the LGBT community, as a vulnerable group? In order to solve it, the deductive approach method is used, aiming, at first, to come to the operating logic of the InterAmerican System, focusing on the advisory function of the Inter-American Court; to verify the main aspects regarding the protection of vulnerable groups from the perspective of the American Convention; and, finally, to critically analyze the Advisory Opinion 24/2017, issued by the Court, which deals with the protection that should be granted by the States to the LGBT community. At last, it is concluded that the Court understands that the States must adopt protective measures towards this group, avoiding any kind of discrimination and eradicating, or at least reducing, the violence that results from gender and sexual identity.

Keywords: LGBT community - Inter-American Court of Human Rights - Vulnerable groups Advisory Function - Advisory Opinion 24/2017 - Inter-American System

\section{Introdução}

Desde meados do Século $X X$ já se tem notícia de organismos internacionais criados com o intuito de estabelecer diretrizes e de fortalecer determinados entendimentos, no sentido de valorização da proteção de direitos humanos, perante a comunidade internacional. Citam-se, como exemplos, a Liga das Nações e a Organização Internacional do Trabalho. Foi, contudo, com o fim da Segunda Guerra Mundial que, de fato, estruturaram-se sistemas com maior força vinculante e maior âmbito de proteção e de garantia em relação aos direitos humanos, objetivando-se, pois, evitar a repetição da violação massiva desses direitos como a que ocorreu no período sombrio da Segunda Grande Guerra.

Nesse contexto, trabalha-se com o Sistema Interamericano de Proteção aos Direitos Humanos, tendo-se como foco, no presente artigo, a atuação da Corte Interamericana de 
Direitos Humanos (Corte IDH), enquanto órgão de jurisdição internacional e intérprete autêntica e última do Pacto de San José da Costa Rica. A Corte Interamericana, notadamente, desempenha as funções consultiva e jurisdicional, firmando entendimentos e reforçando cada vez mais a lógica de proteção perante os países que reconhecem a sua competência. Diante desse cenário, importante trazer para a discussão a situação dos grupos em situação de vulnerabilidade, haja vista que esses, não raras vezes, encontram-se desprotegidos (e esquecidos) no contexto interno, necessitando recorrer aos órgãos internacionais de proteção.

É diante de tal quadro, portanto, que exsurge a problemática a ser trabalhada aqui: qual o posicionamento adotado pela Corte Interamericana de Direitos Humanos na Opinião Consultiva 24/2017 no que tange aos direitos da comunidade LGBT, enquanto grupo em situação de vulnerabilidade? O interesse em trabalhar com a comunidade LGBT, especificamente, emerge em razão dos debates atuais que circundam esse grupo (1), procurando-se, assim, averiguar como o sistema internacional vem analisando as nuances que circundam o tema, na medida em que deve o País estar atento ao corpus iuris interamericano, isto é, ao aparato jurídico e jurisprudencial internacional referente aos direitos humanos.

Assim, para responder o problema suscitado, utilizar-se-á como método de abordagem o dedutivo, partindo-se de uma perspectiva geral para a particular, a partir de uma análise bibliográfica e, também, da Opinião Consultiva emitida pela Corte Interamericana. O método procedimental, por sua vez, consistirá no método analítico, e a técnica de pesquisa na utilização de documentação indireta. Primeiramente, então, abordar-se-á a lógica de atuação da Corte Interamericana de Direitos Humanos (Corte IDH), com foco na sua função consultiva; num segundo momento verificar-se-ão os principais aspectos no que tange à proteção dos grupos em situação de vulnerabilidade sob a ótica da Convenção Americana sobre Direitos Humanos; e, por fim, analisar-se-á criticamente a Opinião Consultiva 24/2017, emitida pela Corte Interamericana de Direitos Humanos, tratando da proteção conferida à comunidade LGBT.

\section{A Corte IDH como intérprete autêntica e última da Convenção Americana e o exercício da sua função consultiva}

O Sistema Interamericano de Proteção aos Direitos Humanos tem como aparato institucional a Comissão e a Corte Interamericana de Direitos Humanos, órgãos dotados de competências específicas para a promoção e na proteção de direitos no cenário da América Latina. A Corte, em particular, é um órgão de jurisdição internacional, atua como verdadeira guardiã e intérprete última e autêntica da Convenção Americana sobre Direitos Humanos, também conhecida como Pacto de San José da Costa Rica. A dupla função conferida à Corte IDH: consultiva e contenciosa (jurisdicional), está prevista nos artigos $64^{(2)}$ e 66, da Convenção Americana, respectivamente, vinculando os estados que reconhecem a sua competência às determinações e interpretações construídas através das sentenças contenciosas e das opiniões consultivas.

(1) Cita-se como exemplo a Ação Direta de Inconstitucionalidade por Omissão 26, que trata da possibilidade de enquadrar a LGBTfobia como crime de racismo.

(2) Artigo 64. 1. "Os Estados membros da Organização poderão consultar a Corte sobre a interpretação desta Convenção ou de outros tratados concernentes à proteção dos direitos humanos nos Estados americanos. Também poderão consultá-la, no que Ihes compete, os órgãos enumerados no capítulo X da Carta da Organização dos Estados Americanos, reformada pelo Protocolo de Buenos Aires. 2. A Corte, a pedido de um Estado membro da Organização, poderá emitir pareceres sobre a compatibilidade entre qualquer de suas leis internas e os mencionados instrumentos internacionais. Organização dos Estados Americanos. Convenção Americana sobre Direitos Humanos (1969). https://www.cidh.oas.org/basicos/portugues/c.convencao_americana.htm

(3) Artigo 29: "Nenhuma disposição desta Convenção pode ser interpretada no sentido de: a. permitir a qualquer dos Estados Partes, grupo ou pessoa, suprimir o gozo e exercício dos direitos e liberdades reconhecidos na Convenção ou limitá-los em maior medida do que a nela prevista; b. limitar o gozo e exercício de qualquer direito ou liberdade que possam ser reconhecidos de acordo com as leis de qualquer dos Estados Partes ou de acordo com outra convenção em que seja parte um dos referidos Estados; c. excluir outros direitos e garantias que são inerentes ao ser humano ou que decorrem da forma democrática representativa de governo; e d. excluir ou limitar o efeito que possam produzir a Declaração Americana dos Direitos e Deveres do Homem e outros atos internacionais da mesma natureza". Organização dos Estados Americanos (1969). Convenção Americana sobre Direitos Humanos. https://www. cidh.oas.org/basicos/portugues/c.convencao_americana.htm

(4) Artigo 31. "Poderão ser incluídos no regime de proteção desta Convenção outros direitos e liberdades que forem reconhecidos de acordo com os processos estabelecidos nos artigos 76 e 77". Organização dos Estados Americanos (1969). Convenção Americana sobre Direitos Humanos. https://www.cidh.oas.org/basicos/portugues/c.convencao_americana.htm 
A atuação da Corte Interamericana de Direitos Humanos no que tange a grupos em situação de vulnerabilidade: Análise da Opinião Consultiva 24/2017

El desempeño de la Corte Interamericana de Derechos Humanos en relación con los grupos en situación de vulnerabilidad: Análisis de la Opinión Consultiva 24/2017

The proceeding of the Inter-American Court of Human Rights regarding vulnerable groups: An analysis of Advisory Opinion 24/2017

Num primeiro momento, ainda, cabe destacar o disposto nos artigos $29^{(3)}$ e $31^{(4)}$ da Convenção, os quais estão atrelados à ideia de uma cláusula aberta, que possibilita diferentes interpretações do texto legal, de acordo com o contexto e com o período em que é feita a análise, sempre objetivando-se maior proteção aos direitos humanos, de modo que "toda e qualquer modificação ou alteração cultural influencia e atinge, também, diretamente, a interpretação constitucional" (Leal, 2007, p. 115). Essa ideia de "cláusula aberta" é trabalhada por Peter Häberle, ao tratar da Constituição enquanto produto cultural, inserida em um contexto de uma sociedade aberta de intérpretes (Leal, 2007), ideia que pode ser estendida, também, no cenário da Convenção Americana, cujos conteúdos não têm um sentido interpretativo fixo e rígido, mas que evolui e se transforma com o tempo, procurando a máxima garantia e efetividade dos direitos humanos. Além disso, podem ser considerados direitos humanos, protegidos e assegurados pela Convenção Americana, não somente os que estão expressamente nela elencados e definidos, mas também outros que sejam reconhecidos ao se seguir os procedimentos abarcados pelos artigos 76 e 77 , da Convenção(5), consubstanciando o que se convencionou chamar de corpus iuris interamericano.

Notadamente no que tange à função consultiva, objeto central do presente trabalho, tem-se que se trata da competência conferida à Corte IDH para "interpretar normas jurídicas internacionais, fixando o seu alcance e conteúdo, mesmo na ausência de casos contenciosos" (Ramos, 2001, citado em Correia, 2008, p. 135). Assim sendo, é possível sanar dúvidas e imprecisões, junto a um órgão internacional com competência para tanto, mesmo quando não se está diante de um procedimento contencioso, o que vem a fortalecer a capacidade da Organização dos Estados Americanos, bem como do Sistema Interamericano de Proteção aos Direitos Humanos, de solucionar problemas interpretativos concernentes à aplicação da Convenção Americana, especialmente por não haver, no procedimento consultivo, partes envolvidas, nem um litígio a resolver (Correia, 2008). Assim, por um lado, permite exercer um controle global sobre a forma como os Estados, em seu conjunto, interpretam e aplicam a Convenção, corrigindo qualquer desvio de entendimento. Por outro lado, permite esclarecer o emprego do procedimento contencioso, evitando uma confrontação com os Estadospartes (Correia, 2008, pp. 135-136).

Nessa senda, a Corte Interamericana é considerada o Tribunal internacional com a mais ampla função consultiva, de modo que la obligación de los órganos del Estado de respetar y garantizar los derechos, lo ha señalado directa y claramente la Corte Interamericna de Derechos Humanos como intérprete último de tales convenciones em el ámbito regional (Alcalá, 2000, p. 57).

Entretanto, alguns limites a essa competência são estabelecidos, sendo que Zovatto aponta como três principais a noção de que a Corte somente pode exercer essa função com relação à interpretação de documentos que versem diretamente sobre a proteção de direitos humanos; a inviabilidade de exercício da consulta como forma de desvirtuar ou corromper a função jurisdicional do Tribunal; e, por fim, a possibilidade da Corte abster-se diante de um caso específico, caso entenda que a consulta possa desnaturalizar a sua função consultiva. Veja-se:

El primer grupo viene dado por la circunstancia de que sólo puede conocer, dentro de esta función, sobre la interpretación de tratados en que este directamente implicada la protección de los derechos humanos en un Estado Miembro del Sistema Interamericano.

Un segundo grupo de limitaciones se desprende de la inadmisibilidad de toda solicitud de consulta que conduzca a desvirtuar la jurisdicción contenciosa de la Corte o, en general, a debilitar o alterar el sistema previsto por la Convención, de manera que puedan verse menoscabados los derechos de las víctimas de eventuales violaciones de los derechos humanos.

Finalmente, en tercer lugar, la Corte deberá considerar las circunstancias de cada caso y, si por razones determinantes concluye que no sería posible emitir la opinión solicitada sin violentar esos límites y desnaturalizar su función consultiva, se abstendrá de responderla por decisión motivada (Zovatto, 1988, pp. 46-47).

São dois os tipos de pareceres consultivos que podem ser emitidos pela Corte IDH, ambos previstos no artigo 64 da Convenção Americana, referindo-se à sua competência material. O primeiro trata-se da interpretação da própria Convenção ou de outros tratados internacionais sobre direitos humanos (artigo 64.1). Cabe, dentro do termo "outros

(5) Veja-se Organização dos Estados Americanos. Convenção Americana sobre Direitos Humanos (1969). https://www.cidh.oas.org/ basicos/portugues/c.convencao_americana.htm 
tratados", conforme próprio entendimento da Corte IDH ${ }^{(6)}$, todo e qualquer tratado internacional "aplicável nos Estados americanos, independentemente de que seja bilateral ou multilateral, de qual seja ou possam ser partes Estados alheios ao sistema interamericano" (Correia, 2008, p. 145), isto é, uma competência bastante ampla.

O segundo, por sua vez, trata da possibilidade de a Corte emitir um parecer de compatibilidade entre as leis internas de determinado Estado com os referidos documentos jurídicos mencionados (artigo 64.2) ${ }^{(7)}$. Confere-se aqui, também, uma competência ampla, larga, pois, ao tratar do termo "leis internas", poder-se-ia pensar na exclusão da análise de projetos de lei, o que não foi o entendimento adotado pela Corte IDH. "Abster-se de atender à solicitação de um Governo porque se trata de um projeto de lei e não de lei em vigor poderia, em alguns casos, forçar dito Governo a violar a Convenção" (Correia, 2008, p. 146), desse modo, dá-se uma interpretação extensiva à expressão "leis internas".

Contudo, a Corte IDH não está obrigada a atender todo e qualquer pedido de consulta, indistintamente. Poderá, quando entender cabível, negar-se a exercer tal função, a citar como exemplo quando a consulta "está sendo utilizada como instrumento de um debate político com a finalidade de afetar o resultado do processo legislativo interno" (Correia, 2008, p. 146). Foi o que ocorreu, por exemplo, quando da solicitação de emissão de opinião consultiva acerca do impeachment, solicitação que foi negada pela Corte IDH, em 29 de maio de 2018.

Indo além, refere-se que a Corte Interamericana não exerce, de ofício, a competência consultiva, sendo necessária sua provocação pelos sujeitos legitimados. Podem solicitar parecer qualquer Estado-membro da Organização dos Estados Americanos, assim como todos os órgãos mencionados no capítulo X, da Carta da OEA. Desse modo, ainda que determinado Estado não tenha ratificado a Convenção Americana, poderá encaminhar um pedido de consulta para a Corte.
Os requisitos formais da consulta estão previstos nos artigos 70 a 72 do Regulamento da Corte Interamericana, cabendo destacar os seguintes: a) os questionamentos deverão ser formulados de forma clara e precisa; b) deverão ser indicadas as disposições cuja interpretação é solicitada; c) caso a solicitação seja referente a outros tratados, o tratado deverá ser devidamente identificado e as perguntas deverão ser específicas; d) caso a solicitação seja referente a interpretação de leis internas, deverá indicar especificamente as disposições direito interno, assim como as da Convenção ou de outro tratado referente à proteção dos direitos humanos ${ }^{(8)}$.

O procedimento a ser seguido está previsto nos artigos 73 a 75 do Regulamento da Corte Interamericana. Quanto a esse aspecto, ressalta-se que a Corte IDH pode optar por não responder a determinada consulta, entretanto a recusa deve ser motivada e fundamentada. Se faz importante, conforme já referido neste trabalho, uma análise minuciosa por parte do Tribunal, no sentido de averiguar se o pedido solicitado não se trata, na verdade, de um caso litigioso encoberto.

Verifica-se que, através das Opiniões Consultivas, passa-se a ter um conhecimento aprofundado e robusto da interpretação da Corte Interamericana quanto às dúvidas que surgem sobre os mais diversos temas, a citar como exemplo a pena de morte (OC $3 / 83$ ), a liberdade de expressão e de pensamento (OC $5 / 85)$, e a identidade de gênero, igualdade e não-discriminação a casais do mesmo sexo

(6) Isso verifica-se, por exemplo, no Parecer Consultivo OC 21/14, ocasião em que a Corte Interamericana se manifestou no sentido de que "o artigo 64.1 da Convenção, ao referir-se à faculdade da Corte de emitir um parecer sobre "outros tratados concernentes à proteção dos direitos humanos nos Estados americanos" é amplo e não restritivo". Complementou, ainda, ao referir a Opinião Consultiva 1/82, que "a competência consultiva da Corte pode ser exercida, em geral, sobre toda disposição concernente à proteção dos direitos humanos, de qualquer tratado internacional aplicável aos Estados americanos, independentemente de que seja bilateral ou multilateral, de qual seja seu objeto principal ou de que sejam ou possam ser partes do mesmo Estados alheios ao Sistema Interamericano" (Corte Interamericana de Direitos Humanos, 2014c, p. 10).

(7) Veja-se Organização dos Estados Americanos (1969). Convenção Americana sobre Direitos Humanos. OEA. https://www.cidh.oas. org/basicos/portugues/c.convencao_americana.htm. Nesse sentido, interessante foi o pronunciamento da Corte Interamericana com relação à solicitação de emissão de opinião consultiva a respeito dos juízos políticos. Para tanto, veja-se: Corte Interamericana de Direitos Humanos (2018). Solicitud de opinión consultiva presentada por la Comisión Interamericana de Derechos Humanos: resolución de la Corte Interamericana de Derechos Humanos, de 29 de mayo de 2018. Corte IDH. http://www.corteidh.or.cr/solicitudoc/ sor 01 18 esp.pdf

(8) Veja-se Organização dos Estados Americanos (2009). Regulamento da Corte Interamericana de Direitos Humanos OEA. http://www. corteidh.or.cr/sitios/reglamento/nov_2009_por.pdf 
A atuação da Corte Interamericana de Direitos Humanos no que tange a grupos em situação de vulnerabilidade: Análise da Opinião Consultiva 24/2017

El desempeño de la Corte Interamericana de Derechos Humanos en relación con los grupos en situación de vulnerabilidad: Análisis de la Opinión Consultiva 24/2017

The proceeding of the Inter-American Court of Human Rights regarding vulnerable groups: An analysis of Advisory Opinion 24/2017

(OC 24/17) (Correia, 2008, pp. 139-141). O instituto, então, vem ao encontro da lógica de integração entre o direito interno e externo, sendo importante ter claro o papel dos Estados, aqui, em estarem atentos às questões levadas ao domínio da Corte. Muito embora as Opiniões Consultivas não sejam vistas como vinculantes por alguns Estados, elas refletem o posicionamento do órgão de jurisdição internacional, o que deve motivá-los a seguir os entendimentos ali firmados ${ }^{(9)}$, evitando, inclusive, alguma condenação na via contenciosa. Na mesma linha, acrescentam Gomes e Gonçalves (2018, p. 140) que: (...) no caso brasileiro impõe-se reconhecer que ainda há a necessidade de se fomentar uma maior utilização das opiniões consultivas da Corte Interamericana por parte dos tribunais judiciais brasileiros, na busca por um direito dialógico, conforme denominam Luiz Flávio Gomes e Valério de Oliveira Mazzuoli, produto da interação feita entre legislação nacional e internacional, ao invés do classista "direito dialético".

Diante do exposto, pode-se dizer que em muito tem a contribuir as opiniões consultivas emitidas pela Corte Interamericana, na medida em que apresentam o entendimento atual e aprofundado da mesma em relação a um tema potencialmente polêmico ou complexo, rodeado de dúvidas e incertezas. Assim, por meio delas é possível pensar-se na adequação das leis internas do País e, também, na observância, pelos juízos e tribunais internos, da interpretação dada pela Corte Interamericana, sob a ótica do Sistema Interamericano, uma vez que vem se firmando o entendimento de que a interpretação da Corte referente às "normas integrantes del corpus iuris interamericano, sea en el ámbito de la ratio decidendi de los casos contenciosos, sea en sus pareceres consultivos, vincula a todos los países sometidos a su jurisdicción" (Leal, 2018b, p.276).

No mesmo sentido, Moura (2018) afirma que os pareceres consultivos emitidos pela Corte de San José, tornam "pública e obrigatória a sua interpretação concernente a dispositivos previstos nos tratados regionais de direitos humanos, definindo sentido e alcance das normas em questão" (p.170). Dito isso, passar-se-á, agora, a expor alguns aspectos relacionados aos grupos em situação de vulnerabilidade, a partir das diretrizes abarcadas pela Convenção Americana sobre Direitos Humanos e da Corte Interamericana, enquanto guardiã e intérprete autêntica da Convenção e do corpo iuris interamericano.

\section{A proteção dos grupos em situação de vulnerabilidade sob a ótica da Convencão Americana sobre direitos humanos}

Inicialmente, é preciso reconhecer-se a existência de diferenças entre os indivíduos que compõem a sociedade atual, marcada pela heterogeneidade, para que, então, seja possível falar na proteção de determinados grupos, mais especificamente, de grupos em situação de vulnerabilidade. A busca pela igualdade tem como nascedouro a Revolução Francesa de 1789, momento em que se passou a defender a igualdade jurídica entre os indivíduos, isto é, uma igualdade meramente formal. Com o passar dos anos, evoluiu-se para o reconhecimento de um conceito de igualdade material, a qual se consubstancia numa igualdade fática, concreta, reconhecendo que indivíduos que se encontram em uma posição desigual (de desvantagem), devem ser tratados também de forma desigual (Siqueira, 2009, pp. 227-228).

Nessa perspectiva passou-se, também, a falar em ações afirmativas, políticas públicas de inclusão, e amparo jurídico maior a esses grupos: tais medidas baseavam-se no tratamento desigual, tido como o método mais eficaz para tentar corrigir as desigualdades. As minorias ou grupos sociais mais vulneráveis receberiam, então, algumas vantagens em relação às classes privilegiadas, como forma de amenizar as diferenças gritantes na sociedade. Vale frisar que "minorias" não significa um segmento social com pouca quantidade de pessoas, mas, sim, um grupo desamparado, que fica impossibilitado de exercer direitos fundamentais e de ter seus interesses reconhecidos no âmbito social e jurídico (Leite, 2011, p. 52).

A busca pela igualdade material dá-se tanto através de uma dimensão positiva

(9) É possível pensar, a partir dessa lógica, na noção de uma dimensão objetiva no que tange aos direitos humanos que compõem o corpus iuris interamericano, e no que se refere à própria jurisprudência da Corte de San José, na medida em que, ao firmar entendimentos nas suas decisões contenciosas e na emissão dos pareceres consultivos, ela está traçando diretrizes e impulsos a serem seguidos por todos os Estados-partes. Seguindo essa linha, Leal afirma que "Ios fundamentos de la decisión sirven como directiva para os Estados, indicando el sentido en que deben actuar en la implementación y concretización de los derechos humanos protegidos por el Sistema Interamericano" (Leal, 2018b, p. 276). 
quanto negativa. Positiva, pois requer a atuação estatal em determinados casos, promovendo e protegendo direitos humanos e fundamentais, e negativa no sentido de abstenção estatal, no exercício da não-discriminação. Nesse sentido vai o entendimento da Corte Interamericana, conforme exposto na Opinião Consultiva 24/2017: “Además, el Tribunal ha sostenido reiteradamente que el artículo 1.1 de la Convención tiene dos vertientes. Por una parte, se encuentra la obligación de respeto (negativa) que implica que los Estados se deben de abstener de cometer actos que conculquen los derechos y libertades fundamentales reconocidas por la Convención; por la otra, se encuentran las obligaciones de garantía (positivas) de los Estados. Estas obligaciones implican el deber de los Estados Parte de organizar todo el aparato gubernamental $y$, en general, todas las estructuras através de las cuales se manifiesta el ejercicio del poder público, de manera tal que sean capaces de asegurar jurídicamente el libre y pleno ejercicio de los derechos humanos" (Corte Interamericana de Dereitos Humanos, 2017, p. 80).

Nesse contexto, cabe referir que a Convenção Americana sobre Direitos Humanos abarca esses dois aspectos, trazendo a previsão expressa do direito à igual proteção perante à lei (artigo 24), bem como do direito de não-discriminação (artigo 1.1). Assim, a Corte Interamericana de Direitos Humanos, na condição de guardiã e intérprete autêntica da Convenção Americana (artigo 67) e de todo o corpus iuris interamericano, exerce um papel de destaque, seja através das sentenças por ela emitidas (função contenciosa, jurisdicional), seja através das opiniões consultivas (função consultiva), vinculando todos os Estados submetidos à sua jurisdição( ${ }^{(10)}$. Leal (2018b) complementa: "es posible afirmar, por lo tanto, que la Corte IDH cumple, en una perspectiva amplia, con la función de guardiana del Sistema Interamericano de Derechos Humanos, constituyéndose, también, en protectora de los grupos en situación de vulnerabilidad, por cuanto la Convención Americana prevé, expresamente, la no-discriminación y la igual protección por la ley como elementos materiales inherentes a la dignidad humana y a la concretización de todos los demás derechos" (p. 276-277).
Verifica-se que os direitos previstos nos artigos 24 e 1.1 da Convenção Americana, isto é, o direito à igual proteção perante à lei e o direito de não-discriminação, respectivamente, são tidos como inerentes ao gênero humano em si, como uma das dimensões da dignidade da pessoa humana e, assim sendo, é possível concluir que, para que se concretize, de fato, o direito à igualdade, é preciso possibilitar-se o exercício de todos os direitos previstos na Convenção Americana, havendo uma relação de complementariedade entre eles, os quais devem ser reconhecidos e exercidos no que toca a todo e qualquer indivíduo, sem discriminações (Leal, 2018b, pp. 277-278).

A Corte Interamericana diversas vezes se pronunciou quanto à necessária proteção dos grupos em situação de vulnerabilidade, alertando, contudo, que o tratamento diferenciado aplicado a eles deve ser sempre razoável e justificado. Ademais, quando se questiona quem seriam os grupos em situação de vulnerabilidade, grupos vulneráveis ou minorias ${ }^{(11)}$, isto é, indivíduos que mereceriam, em princípio, um tratamento diferenciado por se encontrarem em uma posição de desvantagem, não se vislumbra uma resposta pronta trazida pelo referido órgão de jurisdição internacional. A Corte IDH, nas decisões que versam sobre o tema, não apresenta uma classificação ou critérios objetivos de reconhecimento desses grupos. O que ocorre, pois, é o diagnóstico, diante do caso concreto a ela exposto, da situação de vulnerabilidade de determinado grupo, a partir da averiguação da situação fática em que ele se encontra naquele momento específico. Assim, de forma a

(10) Veja-se Organização dos Estados Americanos (1969). Convenção Americana sobre Direitos Humanos. OEA. https://www.cidh.oas. org/basicos/portugues/c.convencao americana.htm

(11) Os conceitos de "minorias", "grupos vulneráveis", ou ainda "grupos em situação de vulnerabilidade", não se confundem. Apesar de serem utilizados, não raras vezes, como sinônimos, não o são. Assim, de forma sucinta, por não ser o objeto central do presente trabalho, pode-se dizer que os grupos vulneráveis são indivíduos que contam com um alto grau de chance de serem ofendidos ou atacados, entretanto, não possuem uma identidade, não detém um traço comum entre si, ao passo que as minorias são sujeitos conectados, com um traço cultural comum, e é esse traço cultural que difere o grupo dos demais integrantes da sociedade (Siqueira \& Castro, 2017, pp. 109-111). Grupos em situação de vulnerabilidade, por fim, é uma denominação utilizada especialmente pela Corte Interamericana de Direitos Humanos, ao tratar de grupos que sofrem algum tipo de discriminação (racial, social, étnica, de gênero, em razão da orientação sexual, etc.), a partir de uma análise feita no caso concreto. Veja-se Leal, M. (2018). Derechos de los grupos en situación de vulnerabilidad: no discriminación e interseccionalidad en la perspectiva de la Corte Interamericana de Derechos Humanos. In C. Landa, Derechos fundamentales: Actas de las III Jornadas Nacionales de Derechos Fundamentales (pp. 271-287). Palestra Editores. Para maiores referências acerca do tema, veja-se também Séguin, E. (2002). Minorias e grupos vulneráveis: uma abordagem jurídica. Forense. 
A atuação da Corte Interamericana de Direitos Humanos no que tange a grupos em situação de vulnerabilidade: Análise da Opinião Consultiva 24/2017

El desempeño de la Corte Interamericana de Derechos Humanos en relación con los grupos en situación de vulnerabilidad: Análisis de la Opinión Consultiva 24/2017

The proceeding of the Inter-American Court of Human Rights regarding vulnerable groups: An analysis of Advisory Opinion 24/2017

evitar qualquer estigmatização, generalização e classificação prévia, a Corte IDH opta pela análise da situação em concreto acerca de se determinado grupo encontra-se em uma situação de vulnerabilidade que requeira um tratamento desigual e diferenciado ou especial proteção (Luna, 2009, p. 121).

Com isso, verifica-se, nas sentenças e também nas opiniões consultivas, não o reconhecimento do índio como grupo vulnerável, mas sim do índio que se encontra em uma situação em que não consegue concretizar um processo de demarcação de terras; não o reconhecimento das crianças como grupo vulnerável, mas de crianças que moram nas ruas e encontram-se desamparadas, e assim sucessivamente (Beloff \& Clérico, 2016, pp. 145-146). Isso, portanto, reforça a ideia de reconhecimento da situação vulnerável através de uma dimensão concreta, e não baseada em critérios abstratos e classificações prévias, cabendo enfatizar, contudo, que "la vulnerabilidad no necesita ser "real", bastando que sea "presunta" o apenas "percebida" (Leal, 2018b, p. 281).

A partir desse recorte, passar-se-á, agora, a analisar a Opinião Consultiva 24/2017, emitida pela Corte Interamericana em resposta a uma solicitação formulada pelo Estado da Costa Rica, no intuito de ver esclarecidos determinados dispositivos da Convenção Americana que tocam, especificamente, em direitos relacionados às pessoas LGBT.

\section{Análise de caso: Opinião Consultiva 24/2017 - Identidade de gênero, igualdade e não- discriminaçăo a casais do mesmo sexo}

As discussões acerca dos direitos das pessoas LGBT são tema latente no cenário da América Latina, tendo como pauta questões tais como a possibilidade de casamento entre casais do mesmo sexo, direitos hereditários, possibilidade de alteração no nome por via administrativa e/ou judicial, cirurgias de mudança de sexo, adoção por casais LGBT, dentre outras. É nesse contexto, pois, que a Corte Interamericana de Direitos Humanos emite a Opinião Consultiva $N^{\circ} 24$, a qual passou a servir de norte e parâmetro convencional para a adoção de posicionamentos por parte dos países que integram o Sistema Interamericano. Cita-se, como exemplo, o próprio caso brasileiro, que, em março de 2018, na Ação Direta de Inconstitucionalidade (ADI) $N^{\circ} 4275$, julgou a possibilidade de substituição do nome no Registro Civil, pela via administrativa, sem necessidade de realização de cirurgia de transgenitalização, citando a própria OC 24/2017, a qual passa-se a analisar na sequência.

A Consulta foi requerida pelo Estado da Costa Rica em 18 de maio de 2016, tendo como base o disposto nos artigos
64.1 e 64.2 da Convenção Americana sobre Direitos Humanos, os quais tratam da competência consultiva da Corte IDH. Traz questionamentos quanto à interpretação e ao alcance dos artigos 11.2 (direito à intimidade e à vida privada); 18 (direito ao nome); e 24 (igualdade perante à lei), com relação ao artigo 1 (direito à não discriminação), todos da Convenção Americana, no que tange a questões relativas à comunidade LGBT (lésbicas, gays, bissexuais, travestis, transgêneros e transexuais) (Corte Interamericana de Dereitos Humanos, 2017, p.3).

Os questionamentos levados à Corte IDH foram os seguintes:

a) Levando em consideração que a identidade de gênero é uma categoria protegida pelos artigos 1 e 24, da Convenção Americana, além do estabelecido nos artigos 11.2 e 18, também da Convenção, tal proteção contempla que o Estado deva reconhecer e facilitar a mudança de nome das pessoas, de acordo com a identidade de gênero de cada uma?

b) Caso a resposta anterior seja positiva, poder-se-ia considerar contrário à Convenção o fato de que a pessoa interessada em modificar o seu nome somente possa fazê-lo pela via judicial, não existindo procedimento para tanto na via administrativa?

c) Poder-se-ia entender que o artigo 54 do Código Civil da Costa Rica deve ser interpretado, de acordo com a Convenção Americana, no sentido de que as pessoas que desejam mudar o seu nome a partir da sua identidade de gênero não estão obrigadas a submeter-se a um processo judicial, devendo o Estado prover um trâmite administrativo rápido, gratuito e acessível para exercer esse direito humano?

d) Levando em consideração que a não discriminação por motivos de orientação sexual é uma categoria protegida pelos artigos 1 e 24 da Convenção, além do estabelecido no artigo 11.2, essa proteção contempla que o Estado reconheça todos os direitos patrimoniais que derivam do vínculo entre pessoas do mesmo sexo? 
e) Caso a resposta anterior seja positiva, é necessária a existência de uma figura jurídica que regule os vínculos entre pessoas do mesmo sexo, para que o Estado reconheça todos os direitos patrimoniais que decorrem dessa relação? (Corte Interamericana de Dereitos Humanos, 2017, pp. 4-5) ${ }^{(12)}$.

Ao desenvolver o tema, a Corte inicialmente refere a importância da temática abordada, qual seja, a proteção dos direitos das pessoas LGBT, tendo-se em vista a sua condição de minoria, que historicamente vem sendo vítima de discriminação estrutural, estigmatização e diversas formas de violência e violações de direitos fundamentais ${ }^{(13)}$. Pontua ainda que, por diversas vezes, a Assembleia Geral da OEA, através de resoluções, expressou que essas pessoas estão sujeitas a diversas formas de violência e discriminação, condenando atos de violência, violações de direitos humanos e todas as formas de discriminação por motivos de orientação sexual e identidade ou expressão de gênero. Tais discriminações se manifestam de diversas formas, refletindo em muitos direitos como o direito à saúde, ao trabalho, à seguridade social e à educação e, não raras vezes, elas se potencializam pela ingerência de fatores como a pobreza, o sexo, a origem étnica, a religião e a idade (Corte Interamericana de Dereitos Humanos, 2017, p. 22, 26).

Nesse sentido, complementa que alguns Estados já vêm adotando políticas públicas e implementando ações no sentido de reconhecer, prevenir e reduzir essa situação de violência e discriminação que sofrem as pessoas LGBT, citando, inclusive, o Brasil como exemplo de Estado que atuou nesse sentido, através da criação, em 2010, de um Conselho Nacional de Combate à Discriminação (Corte Interamericana de Dereitos Humanos, 2017, p. 27).

No que tange ao direito à igualdade, a Corte sustenta que é uma dimensão indissociável do conceito de dignidade humana e, além disso, tanto o direito à igualdade, previsto no artigo 24, como o direito à não-discriminação, previsto no artigo 1 , são considerados, pela jurisprudência do Tribunal, normas de jus cogens. Nesse cenário, as questões de identidade de gênero e sexual estão intimamente conectadas com a noção de liberdade e ao direito à vida privada, devendo todo o ser humano poder autodeterminar-se da forma como se percebe e se identifica (independentemente das questões biológicas), sem que, decorrente disso, resulte qualquer tipo de discriminação ou violação, de modo que condutas nesse sentido passam a ser consideradas uma violação à Convenção Americana. É com esse viés, portanto, que devem trabalhar os Estados, adotando medidas e traçando estratégias para evitar tratamentos diferenciados (Corte Interamericana de Dereitos Humanos, 2017, pp. 32; 47-48).

Quanto aos questionamentos suscitados pelo Estado da Costa Rica, a Corte IDH se manifestou da seguinte forma:

a) A mudança de nome, a adequação da imagem, bem como a retificação do sexo e do gênero nos registros e documentos de identidade, para que estejam de acordo com a identidade de gênero autopercebida, é um direito protegido por diversos dispositivos da Convenção Americana (artigos 18, 3, 7.1, 11.2). Em consequência disso e em conformidade com a obrigação de respeitar e garantir os direitos sem discriminação (artigos 1.1 e 24), e em razão do dever de adotar disposições de direito interno, os Estados estão obrigados a reconhecer, regular e estabelecer procedimentos adequados para tais fins.

(12) Frisa-se que as perguntas devem ser realizadas de modo claro e preciso, identificando os dispositivos que devem ser objeto de interpretação e indicar as considerações que as deram origem, requisitos que foram cumpridos na consulta ora aqui analisada. Além disso, a Corte esclarece que a competência consultiva não deve, em princípio, exercer-se sobre especulações abstratas, devendo haver aplicação previsível a casos concretos que justifiquem o interesse na emissão de uma opinião consultiva. Veja-se Corte Interamericana de Direitos Humanos (2017). Opinión Consultiva OC-24/2017 de 24 de noviembre de 2017 solicitada por la República de Costa Rica: identidad de género, e igualdad y no discriminación a parejas del mismo sexo. Corte IDH. http://www. corteidh.or.cr/docs/opiniones/seriea_24_esp.pdf

(13) Percebe-se que aqui, muito embora não tenha sido trazido nenhum caso concreto, a Corte reconhece a situação de vulnerabilidade das pessoas LGBT's, em razão dos motivos elencados acima (discriminação estruturante e diversas formas de violência que esse grupo vem sofrido ao longo dos anos), podendo-se falar em uma atribuição prévia à esse grupo do conceito de minoria, suscetível a sofrer violações, destacando, inclusive, que "la sola percepción de la homosexualidad o identidad transgénero pone a las personas em situación de riesgo" (Corte Interamericana de Direitos Humanos, 2017, p.22). E, no mesmo sentido, expõe que: "las personas bisexuales, transgénero, mujeres lesbianas y los jóvenes LGBTI se encuentran particularmente expuestos al riesgo de violencia física, psicológica y sexual en el ámbito familiar y comunitario" (Corte Interamericana de Dereitos Humanos, 2017, p. 23), verificandose uma mudança de postura por parte da Corte, que vinha, conforme visto anteriormente, se manifestando no sentido de evitar classificações prévias, procurando verificar a vulnerabilidade de acordo com a situação concreta. 
A atuação da Corte Interamericana de Direitos Humanos no que tange a grupos em situação de vulnerabilidade: Análise da Opinião Consultiva 24/2017

El desempeño de la Corte Interamericana de Derechos Humanos en relación con los grupos en situación de vulnerabilidad: Análisis de la Opinión Consultiva 24/2017

The proceeding of the Inter-American Court of Human Rights regarding vulnerable groups: An analysis of Advisory Opinion 24/2017

b) Os Estados podem optar pelo procedimento mais adequado, levando em conta as particularidades do seu direito interno, dos trâmites para mudança de nome, adequação da imagem e retificação do sexo ou gênero, para que estejam de acordo com a identidade autopercebida, independente da natureza jurisdicional ou administrativa, devendo cumprir com os seguintes requisitos: devem adequar-se integralmente à identidade de gênero autopercebida; devem basear-se unicamente no consentimento livre do solicitante, ficando vedada a exigência de atestados médicos ou psicológicos; devem ser confidenciais, não podendo constar nos documentos a mudança realizada; devem ser gratuitos, na medida do possível; não podem exigir realizações cirúrgicas ou alterações hormonais. Em razão desses quesitos, a Corte entende que, embora não obrigatório, o procedimento administrativo parece melhor se adequar, quando comparado com o procedimento judicial.

c) O artigo 54, do Código Civil da Costa Rica está em conformidade com a Convenção Americana, ressaltando-se que, em consequência de um controle de convencionalidade, o dispositivo deve ser interpretado em conformidade com o padrão previamente estabelecidos, podendo a Costa Rica, criar um procedimento administrativo para tanto.

d) A Convenção Americana protege o vínculo familiar que pode derivar de uma relação de casais do mesmo sexo (artigos 11.2 e 17). A Corte assevera, também, que devem ser protegidos, sem discriminação alguma, todos os direitos patrimoniais que derivam do vínculo familiar entre pessoas do mesmo sexo (artigos 1.1 e 24). Coloca, ainda, que a obrigação internacional dos Estados ultrapassa as questões vinculadas unicamente aos direitos patrimoniais, se projetado a todos os direitos humanos internacionalmente reconhecidos, assim como a todos os direitos e obrigações reconhecidos pelo direito interno de cada Estado.

e) Os Estados devem garantir o acesso a todas as figuras jurídicas já existentes nos ordenamentos jurídicos internos, para assegurar a proteção de todos os direitos das famílias de casas do mesmo sexo, sem discriminação. Para tanto, poderia ser necessário que os Estados modifiquem as figuras existentes, para ampliá-las e estendê-las a casais homossexuais ${ }^{(14)}$

Diante dessa conjuntura, o Tribunal, adotando uma postura inovadora, passa a reconhecer a comunidade LGBT como um grupo em situação de vulnerabilidade a priori, isto é, sem a análise de um caso concreto específico. Há, na verdade, uma conjuntura interamericana que reflete um cenário de violações estruturais, isto é, um quadro de graves violações que se repetem no tempo, mas não um caso individual em análise. Tal postura adotada pela Corte IDH vai, portanto, em sentido contrário à construção jurisprudencial que vinha sendo arquitetada, a qual estava pautada na não classificação prévia dos grupos como grupos vulneráveis, a fim de evitar estigmatizações e catalogações generalistas, citando-se como exemplo, aqui, o Caso Norín Catrimán vs. Chile ${ }^{(15)}$, bem como o Caso Espinoza Gonzáles vs. Peru(16).

Todavia, é possível perceber que o reconhecimento da vulnerabilidade da população LGBT, mesmo sem um caso individual em pauta, operou-se como estratégia no combate ao cenário de violações estruturais, e, também, como forma de atuação preventiva, ao firmar estândares de interpretação e parâmetros mínimos de proteção, fortalecendo a lógica interamericana de proteção. A partir disso, é possível pensar que nem toda a classificação prévia e abstrata tratar-se-á de uma postura estigmatizante, podendo-se revelar, como foi o caso, como um mecanismo de proteção e reconhecimento de uma situação evidente.

Diante do exposto, é importante ter clara a relevância do papel consultivo exercido pela Corte IDH e o que ele representa. A partir dos fundamentos elencados ao longo das opiniões emitidas, pode-se extrair a interpretação de dispositivos da Convenção Americana, bem como dos tratados e demais documentos que se encaixam no conceito de corpus iuris interamericano. Além disso, pode-se clarear questões dúbias e confirmar determinados padrões e ideias, momento a partir do qual os Estados passam a adotar uma mudança de postura, ou reforçar atitudes

(14) Veja-se Corte Interamericana de Direitos Humanos (2017). Opinión Consultiva OC-24/2017 de 24 de noviembre de 2017 solicitada por la República de Costa Rica: identidad de género, e igualdad y no discriminación a parejas del mismo sexo. Corte IDH, pp. 54; 69-70; 72; 79-80; 86. http://www.corteidh.or.cr/docs/opiniones/seriea_24_esp.pdf

(15) Veja-se Corte Interamericana de Direitos Humanos (2014, 29 de mayo). Caso Norín Catrimán y otros (dirigentes, miembros y activista del pueblo indígena mapuche) vs. Chile. http://www.corteidh.or.cr/docs/casos/articulos/seriec_279_esp.pdf

(16) Veja-se Corte Interamericana de Direitos Humanos (2014, 20 de noviembre). Caso Espinoza Gonzáles vs. Perú. http://www.corteidh. or.cr/docs/casos/articulos/seriec_289_esp.pdf 
e estratégias que já se encontram de acordo com a lógica de proteção do Sistema Interamericano de Proteção aos Direitos Humanos. Assim, "su respuesta a la consulta planteada será de gran importancia para los países de la región en la medida en que permitirá precisar las obligaciones estatales en relación con los derechos de las personas LGBTI en el marco de sus obligaciones de respetar y garantizar los derechos humanos a toda persona bajo su jurisdicción" (Corte Interamericana de Dereitos Humanos, 2017, p.13).

Isto é, a partir do que foi dito e reforçado pela Corte ao longo da Opinião Consultiva 24/2017, pode-se extrair interpretações e compreensões a serem analisadas quando se pensarem estratégias e ferramentas de proteção à comunidade LGBT, isto é, nos momentos de criação e implementação de políticas públicas, de criação e adequação da legislação, bem como nos momentos de exercício da função jurisdicional| ${ }^{(17)}$ (como, por exemplo, o que se deu no julgamento da ADI 4277), de modo que haja um diálogo entre o direito interno e o direito externo, e um fortalecimento do Sistema Interamericano como um todo.

\section{Conclusão}

Num primeiro momento, verificou-se que o Sistema Interamericano de Proteção aos Direitos Humanos é composto por dois órgãos que formam o seu aparato institucional: a Comissão e a Corte Interamericana de Direitos Humanos. Ambas exercem papeis de extrema relevância, mas, neste trabalho, cabe especial destaque para a função consultiva desenvolvida pela Corte IDH, consubstanciada na atribuição de analisar consultas solicitadas pelos Estados, referentes à interpretação de dispositivos da Convenção Americana sobre Direitos Humanos ou sobre os demais documentos que incorporam o corpus iuris interamericano. A consulta reflete o posicionamento do Tribunal sobre eventuais dúvidas e interpretações a serem dadas aos dispositivos, contudo, além de sanar as incertezas, ela serve como norte para os demais Estados (dimensão objetiva) integrantes do Sistema, quando esses enfrentarem questões relacionadas, seja pela via legislativa, administrativa ou jurisdicional.

No que toca ao questionamento levantado no início do presente trabalho, qual seja: qual o posicionamento adotado pela Corte Interamericana de Direitos Humanos na Opinião Consultiva 24/2017 no que tange aos direitos da comunidade LGBT, enquanto grupo em situação de vulnerabilidade, tem-se, primeiramente, a averiguação de uma mudança de postura por parte da Corte Interamericana, que vinha, nas suas decisões, entendendo que a noção de vulnerabilidade se compreende a partir da análise de um contexto específico, isto é, a partir da análise de uma situação concreta, evitando qualquer tipo de classificação prévia ou estigmatização. Entretanto, se verificou ao longo da Opinião Consultiva que a Corte IDH percebe a comunidade LGBT como um grupo em situação de vulnerabilidade, em razão da discriminação histórica e dos diversos tipos de violência e violação de direitos humanos que acometem esses indivíduos, pela simples razão decorrente da sua identidade de gênero ou sexual.

Assim, enfatiza a Corte que os Estados devem adotar medidas e ferramentas no sentido de proteção a esse grupo, evitando qualquer tipo de discriminação e erradicando, ou ao menos reduzindo, as violências que decorrem da identidade de gênero e sexual, sendo esse o posicionamento que está de acordo com a Convenção Americana sobre Direitos Humanos e que se coaduna com toda a lógica de proteção fomentada pelo Sistema Interamericano de Proteção, apontamentos esses que merecem ser levados em consideração quando os demais países que integram o Sistema lidarem com situações relacionadas ao tema.

\section{Referências bibliográficas}

Alcalá, H. (2000). Teoría de los derechos fundamentales y los derechos humanos. Ingranusi.

Beloff, M. \& Clérico, L. (2016). Derecho a condiciones de existencia digna y situación de vulnerabilidad en la jurisprudencia de la Corte Interamericana. Estudios Constitucionales, 14(1), 139-178. http://dx.doi.org/10.4067/S071852002016000100005

Correia, T. R. (2008). Corte Interamericana de Direitos Humanos: Repercussão jurídica das opiniões consultivas. Juruá.

Corte Interamericana de Direitos Humanos (2014a, 20 de noviembre). Caso Espinoza Gonzáles vs. Perú. http://www.corteidh.or.cr/docs/casos/ articulos/seriec_289_esp.pdf

Corte Interamericana de Direitos Humanos (2014b, 29 de mayo). Caso Norín Catrimán y otros (dirigentes, miembros y activista del pueblo indígena mapuche) vs. Chile. http://www.corteidh. or.cr/docs/casos/articulos/seriec_279_esp.pdf

(17) Isto é, de modo que todos os Poderes internos (Executivo, Legislativo e Judiciário) estejam atentos para as diretrizes firmadas pela Corte IDH, adotando-se a noção de uma dimensão objetiva dos direitos humanos. 
A atuação da Corte Interamericana de Direitos Humanos no que tange a grupos em situação de vulnerabilidade: Análise da Opinião Consultiva 24/2017

El desempeño de la Corte Interamericana de Derechos Humanos en relación con los grupos en situación de vulnerabilidad: Análisis de la Opinión Consultiva 24/2017

The proceeding of the Inter-American Court of Human Rights regarding vulnerable groups: An analysis of Advisory Opinion 24/2017

Corte Interamericana de Direitos Humanos. (2014c). Parecer Consultivo OC-21/2014 de 19 de agosto de 2014, solicitado pela República Argentina, República Federativa do Brasil, República do Paraguai e República Oriental Do Uruguai: direitos e garantias de crianças no contexto da migração elou em necessidade de proteção internacional. CIDH. http://www.corteidh. or.cr/docs/opiniones/seriea_21_por.pdf

Corte Interamericana de Direitos Humanos. (2017). Opinión Consultiva OC-24/2017 de 24 de noviembre de 2017 solicitada por la República de Costa Rica: identidad de género, e igualdad y no discriminación a parejas del mismo sexo. CIDH. http://www.corteidh.or.cr/docs/opiniones/ seriea_24_esp.pdf

Corte Interamericana de Direitos Humanos. (2018). Solicitud de opinión consultiva presentada por la Comision Interamericana de Derechos Humanos: resolución de la Corte Interamericana De Derechos Humanos, de 29 de mayo de 2018. CIDH. http:// www.corteidh.or.cr/solicitudoc/sor_01_18_esp.pdf

Gomes, E. \& Gonçalves, A. (2018). Breves considerações da competência consultiva da Corte Interamericana de Proteção aos Direitos Humanos à luz das abordagens descolonialistas. In C. Landa, R. Sarlet, I. Wolfgang \& P. Ricardo (org.), Direitos humanos e fundamentais na perspectiva da democracia interamericana (pp. 130-144). Instituto Memória Editora \& Projetos Culturais.

Leal, M. (2007). Jurisdição constitucional aberta: reflexões sobre a legitimidade e os limites da jurisdição constitucional na ordem democrática. Lumen Juris.

Leal, M. (2018a). Corte Interamericana de Direitos Humanos e jurisdição constitucional: interconstitucionalidade e diálogo entre Cortes na perspectiva do Supremo Tribunal Federal. In C. Landa, I. Wolfgang \& P. Ricardo. (org.), Direitos Humanos e Fundamentais na perspectiva da democracia interamericana (pp. 169-201). Instituto Memória.

Leal, M. (2018b). Derechos de los grupos en situación de vulnerabilidad: no discriminación e interseccionalidad en la perspectiva de la Corte Interamericana de Derechos Humanos. In C. Landa, Derechos fundamentales: Actas de las III Jornadas Nacionales de Derechos Fundamentales (pp. 271-287). Palestra Editores.

Leite, C. H. (2011). Direitos humanos (2. ${ }^{\text {a }}$ ed). Lumen Juris.

Luna, F. (2009). Elucidating the Concept of Vulnerability: Layers Not Labels. International Journal of Feminist Approaches to Bioethics, 2(1), 121-139. http://dx.doi.org/10.3138/ijfab.2.1.121

Moura, R. (2018). Julgados da Corte Interamericana sobre casos brasileiros e políticas públicas: reflexões acerca de possíveis influições. Revista de Direito Internacional (UniCEUB), 15(3), 164-177. https://doi. org/10.5102/rdi.v15i3.5683

Organização dos Estados Americanos. (1969). Convenção Americana sobre Direitos Humanos. OEA. https://www.cidh.oas.org/basicos/ portugues/c.convencao_americana.htm

Organização dos Estados Americanos. (2009). Regulamento da Corte Interamericana de Direitos Humanos. OEA. http://www.corteidh.or.cr/ sitios/reglamento/nov_2009_por.pdf

Séguin, E. (2002). Minorias e grupos vulneráveis: uma abordagem jurídica. Forense.

Siqueira, D. (2009). Inclusão social, processo coletivo e minorias no ordenamento jurídico brasileiro. Revista USCS, 10(16), 221-237.

Siqueira, D. \& Castro, L. (2017). Minorias e grupos vulneráveis: a questão terminológica como fator preponderante para uma real inclusão social. Revista Direitos Sociais e Políticas Públicas (UNIFAFIBE), 5(1), 105-122. http://dx.doi.org/10.25245/rdspp.v5i1.219

Zovatto, D. (1988). La interpretación del artículo 27 de la Convención Americana sobre Derechos Humanos en las Opiniones Consultivas de la Corte Interamericana de Derechos Humanos. Revista Instituto Interamericano de Derechos Humanos, 7, 43-65. https://www.corteidh. or.cr/tablas/R06720-3.pdf 